\title{
Possibilidades e limitações da escola pública como agente de educação sexual
}

Cenira Ribeiro Silva*

\section{RESUMO}

Este estudo investigou os fatores que se inter-relacionam na educação sexual feita pela escola pública de $1^{\circ}$ Grau, na região da Grande Passo Fundo, RS. Buscou identificar as possibilidades e as limitações com que contam os diretores e os professores dessas escolas para promover a educação sexual dos alunos e a percepção que a clientela tem da educação sexual aí praticada. Foram entrevistados 135 integrantes de escolas públicas de $1^{\circ} \mathrm{Grau}$, distribuídos entre diretores de escolas $(22,2 \%)$, professores $(33,3 \%)$ e alunos $(44,5 \%)$. Os achados revelam que os mesmos fatores que dificultam a realização da educação sexual na escola podem, também, facilitar essa tarefa, dependendo de como eles se caracterizem. As condições pessoais e profissionais dos professores são citadas como os principais intervenientes na educação sexual por alunos e diretores. Os pro-

* Bióloga. Mestre em Educação. Professora Titular de Biologia Educacional da Universidade de Passo Fundo, RS.

Recebido em 5.3.97 
fessores apontam a falta de estratégias adequadas como o principal fator dificultador do seu trabalho. Conclui-se, dessa forma, que os principais fatores intervenientes na educação sexual na escola pública se vinculam, fundamentalmente, à figura do professor, à sua formação profissional e à sua prática pedagógica.

\section{IDÉIAS INICIAIS}

Capazes de gerar muitos filhos, os pares humanos têm-se mostrado pouco competentes em orientá-los como serem sexuados. Por não perceber as transformações evolutivas de seus filhos como realidade significativa ou por desconhecer o processo de desenvolvimento humano, a grande maioria dos casais brasileiros tem deixado para a escola ou para o "mundo" essa tarefa.

Pesquisa divulgada pela Data Folha em 27 de junho de 1993, sobre a inclusão da educação sexual nas escolas, demonstra que nas dez capitais brasileiras envolvidas nesse trabalho, $86 \%$ das pessoas entrevistadas são favoráveis à realização da educação sexual nas escolas e que somente $36 \%$ desses pais falam com seus filhos sobre o assunto. Por outro lado, a editora FTD realizou, em maio de 1989, pesquisa com 10 mil professores, considerados influentes no mundo escolar, cujo resultado mostra que esses profissionais admitem a necessidade de a escola fazer a educação sexual de seus alunos, mas se sentem despreparados para tal responsabilidade. (Fórum Nacional de Sexualidade Humana, 1994.)

Como Professora de Ciências Naturais no ensino de $1^{\circ}$ Grau e de Biologia, nos seus vários ramos, no $2^{\circ}$ e no $3^{\circ}$ Graus, tenho tido oportunidade de conviver com currículos escolares em que o estudo de um corpo sexuado, vivo e funcionante raramente encontra espaço. Fala-se de como Bactérias e Fungos se reproduzem, enfatiza-se os mecanismos presentes na reprodução sexual dos animais em geral; todavia, a reprodução humana não é tratada com a atenção que merece. Quando chega a hora desse tema não há mais tempo. $\mathrm{O}$ ano letivo acabou e os alunos ficam, mais uma vez, com as perguntas presas na garganta.

Pesquisa que realizei para Dissertação de Mestrado, em 1994, com o título de Experiências Fluberais e Sexualidade Feminina: subsídios para a educação sexual, com mulheres de 15 a 90 anos, revela que a escola, tanto quanta a família, se mostra pouco preparada para abordar questões que possibilitariam a mais adequada compreensão das manifestações sexuais de crianças e de adolescentes. As mulheres mais, velhas 
nem chegam a mencionar a interveniência da escola nas suas vivências sexuais. As entrevistadas adolescentes mencionam a escola como local onde grupos de jovens de sexos diferentes se encontram para trocar confidências, isso contribui para a socialização entre os sexo (FERREIRA, 1984). Os grupos de amigos que ali se formam representam grande depositários das dúvidas e dos questionamentos dos jovens e meio para compartilhar experiências.

A família parece ainda estar preocupada em estabelecer e institucionalizar sistema de alienação quanto à maturidade de suas filhas, sacramentando o sofrimento e o mistério como naturais no processo que conduz a menina a se tornar mulher num mundo sob o domínio masculino (CUNHA, 1994). No trabalho referido anteriormente, as mulheres das mais diferentes idades declaram que só foram orientadas sobre menstruação depois que a mesma já havia ocorrido e que essas orientações se restringiram à adoção de medidas de higiene e de prevenção de complicações com a saúde. Raramente essa tarefa foi assumida pela mãe (SILVA, 1995).

Por outro lado, sabe-se que o menino é impelido a assumir desde cedo o papel de machão no convívio social. Mesmo que ao nível individual ele reconheça a igualdade e a complementariedade de homens e de mulheres, ao nível social ele se vê impelido a manifestar o contrário. Além disso, a crença de que o homem deve apresentar uma performance sexual "normal" ou "supernormal" gera tensões, medos e sofrimentos para o menino. Nesse contexto, não encontrando o apoio necessário nos educadores, tanto da família quanto da escola, os meninos vão para a rua procurando respostas para suas indagações sexuais junto a amigos, a revistas, a filmes pornográficos e a outros meios.

Nas culturas patriarcais como a que caracteriza a sociedade brasileira. O mito da masculinidade impede que as diferenças sexuais sejam vistas coma exigências de complementariedade entre os sexos (FERNÁNDEZ, 1992). O homem é sempre o senhor e como senhor detém o saber. Esse saber envolve, até mesmo, a sexualidade feminina, o que lhe confere maior prestígio e condição de domínio sobre a mulher.

Nunca como nesta hora, de tão graves ameaças ligadas à vivência sexual, se fez tão necessário ouvir os jovens para orientá-los. E preciso criar situações de discussão e de análise das possibilidades e das vulnerabilidades existentes nas suas experiências sexuais. Tradicionalmente pouco se tem considerado as opiniões, as experiências e as percepções que os indivíduos "comuns" têm a respeito da sexualidade, como referencial para sua educação e sua orientação. Contudo, essa prática não tem se re- 
velado eficaz na promoção do bem-estar das crianças, dos jovens e das pessoas em geral.

A superficialidade e o medo parecem ser uma constante na questão da sexualidade humana. As meninas têm medo do desconhecido da menarca. Elas e as mulheres mais maduras têm medo de engravidar fora do casamento, "serem abandonadas e ficarem faladas para sempre". As mães, por sua vez, têm medo de que isso venha ocorrer com suas filhas. Enfim, todas as mulheres se mostram com muito medo da gravidez fora do casamento.

A contradição entre os avanços científicos e tecnológicos referentes ao controle da natalidade e ao aumento do número de meninas que, mesmo com pavor da gravidez fora do casamento, engravidam precocemente, parece evidenciar que o medo da mãe e da família não se limita à gravidez extraconjugal de suas filhas, mas se caracteriza, também, como "medo de saber". Ter conhecimento sobre sexo, sexualidade, gravidez, menstruação, doenças sexualmente transmissíveis, contraceptivos e sobre outros assuntos implica responsabilidade com a educação sexual de suas filhas e de seus filhos. De igual forma, implica assumir a culpa pela omissão dessa educação. Enveredar pelo caminho da sexualidade significa conviver com a insegurança da existência humana. É mais fácil não saber!

Uma entrevistada no trabalho já referido anteriormente, grávida e com experiências sexuais desde os 12 anos de idade, assim se refere à educação sexual feita pela família e pela escola:

"Acho que os pais se fecham para esse assunto. Acham que com sua Família nunca vai acontecer nada. Não basta assustar, isso não resolve. Tem que buscar conhecimento. A escola precisa enfrentar esse assunto, começando pelos pais e de modo claro e direto".

SEDUÇÃO, 17 anos (1994)

Ao se referir à educação sexual, Sedução envolve os mas significativos e tradicionais agentes de educação, a família e a escola. Deixa transparecer um eixo condutor para que a eficácia das ações educativas desses setores seja melhorada. Contudo, a família e a escola não têm vida "de per si". Imbricadas que estão num contexto sociocultural, carregam consigo preconceitos, mitos e tabus, próprios de uma sociedade patriarcal e capitalista, que dificultam e que até impossibilitam as atividades educacionais voltadas às questões sexuais. A visão positivista e androcêntrica contribui para que os agentes educacionais, nem sempre, vislumbrem ou- 
tras possibilidades de construção e de realização pessoais, que não aquelas já sedimentadas nesse contexto.

Concordo com Sedução ao colocar a família e a escola com o mesmo nível de responsabilidade na orientação sexual dos educandos. Por outro lado, vejo agora que a escola não se encontra em condições de subsidiar a família na educação sexual de seus filhos. Neste estudo a escola se revela tão frágil e confusa quanto a família tem se revelado, para promover a educação e a orientação sexuais de crianças e de jovens.

A não formação adequada dos pais e professores como educadores sexuais contribui para que, embora como todo o avanço tecnológico, a educação sexual ainda em moda se caracterize como pseudoliberdade sexual, que só aumenta a confusão e a insegurança dos jovens, trazendo-lhes novas dificuldades. A falta de diálogo entre educadores e educandos impede que pais e professores saibam coisas simples e significativas para a juventude. Poucos são aqueles que sabem, por exemplo, ser mais importante para os jovens saber quais os melhores métodos contraceptivos do que conhecer como ocorre a fecundação.

Embora as mudanças sociais da era industrial e a chegada dos mas diversos e modernos métodos contraceptivos tenham trazido em seu bojo maior liberdade para a práfica sexual, os educadores não têm conseguido se libertar do acanhamento e das meias verdades no trato dos assuntos relativos à vivência sexual. Na maioria das vezes, a educação sexual chega tarde demais, age misteriosamente e passa ao largo das questões principais na vida sexual de um ser humano real, camuflando a verdadeira situação sexual das pessoas (REICH, 1988).

\section{OBJETIVOS}

\section{Geral}

Desvelar os fatores que se inter-relacionam nas condições da Escola Pública como agente de educação sexual, para oferecer curso de Extensão em Educação e Orientação Sexual, que subsidie a ação dos professores como educadores sexuais.

\section{Específicos}

- Investigar as possibilidades e limitações com as quais contam as direções das escolas públicas para promover a educação sexual dos alunos. 
- Identificar as possibilidades e limitações próprias dos professores dessas escolas para assumir a educação sexual em suas classes.

- Desvelar a situação de acomodação e resistência em que se encontram os alunos quanto à educação sexual praticada na escola.

\section{METODOLOGIA}

\section{Sujeitos}

Foram entrevistados 135 integrantes da escola pública do ensino de $1^{\circ}$ Grau, de municípios da região da Grande Passo Fundo, RS. A amostra constitui-se de: $22,2 \%$ de diretores de escolas, $33,3 \%$ de professores e $44,5 \%$ de alunos do $1^{\circ}$ Grau.

A divisão da amostra entre os diferentes componentes do universo da escola permite caracterizar como cada um desses segmentos percebe a questão da educação sexual dentro da mesma, buscando diminuir os desvios que as diferentes experiências escolares vividas pelos sujeitos que os compõem possam imprimir à realidade da educação sexual na escola pública dessa região.

\section{Instrumento/Procedimento}

Os sujeitos responderam à entrevista dialógica, semi-estruturada, com questões abertas, comuns a todos os entrevistados: "Qual a sua opinião sobre a educação sexual na escola? Quais os fatores que ajudam e quail os' fatores que dificultam a prática da educação sexual na escola?"

As questões das entrevistas foram elaboradas a partir de respostas retiradas de entrevistas gravadas com sujeitos, de diversas idades, sobre a ação da escola na sua orientação sexual.

As entrevistas foram realizadas pela pesquisadora e pelas alunas do $3^{\circ}$ nível do curso de Pedagogia Séries Iniciais, semestre I, de 1995. Os dados recolhidos foram analisados utilizando-se o método de Análise de Conteúdo. A coleta de dados e as fases de unitarização e de categorização da analise dos mesmos foram realizadas com a participação direta das alunas do curso de Pedagogia. As demais fases, interpretação e discussão dos resultados da pesquisa, tiveram a participação indireta das alunas. 


\section{RESULTADOS}

Embora a abordagem desta pesquisa não priorize os aspectos quantitativos de suas informações, é importante salientar a sensível diferença nos percentuais referentes à percepção dos níveis de dificuldades e dos níveis de possibilidades revelados pelos diferentes grupos de entrevistados para que a educação sexual seja realizada pela escola.

Num percentual de $70 \%$ das respostas contra $30 \%$, os diretores de escolas consultados ressaltam as dificuldades existentes para que a escola faça a educação de seus alunos. As respostas dos professores revelam que, na percepção deste segmento da escola os fatores que dificultam têm seu percentual diminuído para $20 \%$, enquanto os fatores que possibilitam têm seu percentual elevado para $80 \%$. As respostas dos alunos revelam um maior equilíbrio na percepção entre os fatores que dificultam e os fatores que facilitam a educação sexual na escola, $55 \%$ e $45 \%$ respectivamente. Resumindo tem-se o seguinte quadro:

\section{Para os diretores de escolas:}

- fatores que dificultam a realização da educação sexual na escola $-70 \%$

$-30 \%$

2. Para os professores:

- fatores que dificultam a realização da educação sexual na escola $-20 \%$

- fatores que ajudam a realização da educação sexual na escola $-80 \%$

\section{Para os alunos:}

- fatores que dificultam a realização da educação sexual na escola $-55 \%$

- fatores que ajudam a realização da educação sexual na escola $-45 \%$

Analisando-se os fatores que são apontados como dificultadores e os fatores considerados facilitadores da ação da escola na educação sexual 
dos alunos de $1^{\circ} \mathrm{Grau}$, verificam-se as seguintes categorias, em ordem de frequiência:

\section{dificultam}

1. condições e formação dos professores;

2. estratégias utilizadas no trabalho;

3. características dos pais;

4. características dos alunos;

5. dificuldades originadas fora da relação família-escola;

6. necessidade da participação de especialistas de fora da escola.

\section{facilitam}

1. formação dos professores;

2. estratégias utilizadas no trabalho;

3. características dos pais;

4. características dos alunos;

5. progresso dos meios de comunicação;

6. relações interpessoais;

7. material didático.

Corno se percebe, a grande maioria das categorias apontadas como fatores dificultadores aparece, também, como fatores possibilitadores da educação sexual na escola, isto conforme eles possam estar caracterizados. As condições pessoais e a formação profissional do professor, as estratégias utilizadas para fazer a educação sexual, as condições dos pais, as condições dos alunos e os meios de comunicação aparecem tanto como fatores dificultadores quanto como fatores facilitadores dessa tarefa. Os fatores externos à relação família-escola só aparece como fator dificultador e a categoria material didático é vista, apenas, como fator facilitador da educação sexual na escola.

Para os diretores de escolas e para os alunos, a formação e as condições pessoais do professor aparecem como o principal elemento que pode ser tanto dificultador como possibilitador da realização da educação sexual pela escola. Na opinião dos professores, as condições do profissional da educação aparecem em último lugar entre os elementos que interferem na realização da educação sexual pela escola. $O$ fator que eles citam como o principal interveniente nessa tarefa são as estratégias utilizadas.

A discussão de todas as categories de análise emergidas nesta pesquisa pode provocar o surgimento de muitos e longos trabalhos. Contudo, nesta ocasião quero me ater aos temas: formação do professor e 
estratégias por ele utilizadas para a educação sexual de seus alunos, por terem eles se revelado muito significativos para os sujeitos desta investigação e por representarem um desafio para mim, que trabalho na formação de professores.

\section{1 - O Professor, sua Formação e seu Desempenho}

Dentre as condições dos professores apontadas pelos entrevistados como fator que facilita a educação sexual na escola, a sua formação adequada e citada com preponderância por diretores de escolas a pelos alunos. Mesmo os professores, embora não com a mesma ênfase anterior, ressaltam a conveniente formação do docente como se constituindo num elemento possibilitador da realização da educação sexual na escola. O professor é percebido, na maioria dos casos, como um profissional mal preparado a inseguro para tratar dos assuntos ligados à sexualidade de seus alunos: "Às vezes, os alunos são mais esclarecidos sobre sexo do que os professores." "A vergonha que os professores têm de falar sobre sexo dificulta a educação sexual." "Os professores só estão preparados para suas disciplinas específicas e fogem do assunto sexo."

O Guia de Orientação Sexual (1994) ressalta pesquisa feita pela Editora FTD (1989) com 10 mil professores de escolas públicas e particulares, considerados com poder decisório junto às direções e às coordenações das escolas e junto aos seus colegas, cujos resultados apontam que $84,3 \%$ dos entrevistados acham que nã o tiveram uma boa educação sexual, $75,9 \%$ desses mesmos sujeitos consideram importante que a educação sexual seja feita nas escolas, mas não se sentem em condições de fazê-la. Elas acreditam não ter vivido condições de formação profissional adequadas para lidar com as questões ligadas à sexualidade de seus alunos.

Por outro lado, Max Sugar (1992, p. 58), referindo-se às colocações de Johnson, diz: "A educação sexual para pessoas normais pode constituir-se num problema inadministrável para muitos educadores e pais." $\mathrm{O}$ mesmo autor, mencionando Gorgon, afirma que não são freqüentes os casos de professores, enfermeiros e médicos especialmente bons em educação sexual, e que boa parte da educação sexual de crianças e de jovens é feita por pessoas formalmente não preparadas para isso.

Por seu turno, os alunos enviam através de seus depoimentos um "SOS" professores e um "SOS" escola. A contradição entre a necessidade que os alunos têm de educação sexual e as condições que a escola apre- 
senta para atendê-la é apontada pelos alunos, pelos professores e pelos diretores. Tal estado de coisas revela que a carência de conhecimentos e de formação sobre a sexualidade humana não se restringe aos alunos, o que seria até certo ponto admissível. O que mais preocupa é o fato dessas limitações se estenderem aos professores a aos diretores de escolas. Essa realidade na escola, associada aos tabus. preconceitos e omissões, que parecem acompanhar o desconhecimento das questões sexuais de seus filhos por parte da família brasileira. representam um fator complicador da vida dos indivíduos.

Sabe-se que a gravidez precoce não representa um fato novo. Entre nossas avos eram comuns os casamentos de adolescentes de 15, 16 e até de menor idade que essas. Mulheres de 18 anos já possuíam 2, 3 ou até mais filhos. Porém, esses filhos eram desejados e até necessários para o contexto em que viviam tais famílias. O que se tornou preocupante é a intensidade com que a gravidez precoce e indesejada vem ocorrendo nos dias atuais no Brasil. Nesses casos, à adolescente grávida só restam três alternativas: o casamento por conveniência, o abortamento ou ser mãe solteira (VITIELLO, 1994).

É claro que nenhuma dessas alternativas representa almejada perspectiva de vida para qualquer adolescente ou para qualquer família, principalmente para aquelas cuja luta pela sobrevivência já é tão difícil em nosso país. A gravidez precoce da mulher solteira se mostra indesejável para ela mesma, para seu parceiro, para sua família e para toda a sociedade. Por outro lado. os avanços tecnológicos na produção de novas drogas a no aperfeiçoamento de técnicas anticonceptivas podem ser considerados bastante satisfatórios. Por quê. então, as mulheres continuam engravidando precocemente e contra sua vontade?

Sem dúvida, foram as conquistas Científicas e tecnológicas no campo da anticoncepção e a comercialização da pílula que ofereceram às mulheres grandes possibilidades de mudança em seus hábitos e em suas limitações na sociedade. Infelizmente, essas transformações não são frutos nem se fizeram acompanhar de ações educativas efetivas, que viabilizassem a plena incorporação de tais avanços. As lacunas no campo educacional e pedagógico na abordagem da sexualidade humana vêm se mostrando acentuadamente claras. Os dados desta pesquisa mostram que, ao mesmo tempo que as práticas de educação sexual são dificultadas por questões culturais, também impedem que sejam criadas oportunidades de transformações e modernização sociais. A formação do professor negligenciada nesse âmbito impede que ele seja instrumentalizado para um desempenho mais adequado às necessidades dos alunos: "Os professores não têm preparo para responder qualquer pergunta do aluno sobre sexo." "As escolas que 
têm professores especializados no assunto têm maior sucesso na educação sexual dos alunos."

A escola se mostra com dificuldades para refletir sua prática pedagógica e em encontrar novas formas de trabalhar. através das quais seja possível fazer a mediação entre a sua função específica de ensinar e as necessidades e condições de vida do novo aluno, que integra seu corpo dicente. Essa dificuldade parece ter sua vertente também nos cursos de formação de professores, nos quais são priorizados os conteúdos específicos em detrimento das disciplinas de Fundamentos da Educação, fundamentos biopsicológicos e sociofilosóficos. "Os professores só querem saber de falar da sua matéria." Não penso que estas disciplinas possam, por si mesmas, resolver a falta de preparação do professor como educador sexual. Este profissional, antes de tudo, viveu e vive numa cultura que não favorece esta formação. Porém, seria mais um espaço a ser conquistado.

A prioridade do enfoque biológico na educação sexual tem concentrado a responsabilidade dessa tarefa nos professores de Ciências e de Biologia. Os professores das demais disciplinas ficam isentos dessa preocupação. Os professores ligados à área biológica, por sua vez, também estão sujeitos aos condicionamentos socioculturais que têm dificultado a educação sexual nas escolas brasileiras. Embora com suposto maior domínio de conhecimentos subsidiadores da educação sexual, poucos são aqueles que enfrentam sem medo esse assunto: "O professor de Ciências é o único que trata de sexo com os alunos." Mesmo os professores ligados à área biológica muitas vezes não conseguem responder as perguntas dos alunos como estes desejariam.

Fora da escola são, predominantemente, os profissionais da área da saúde que se propõem assumir a orientação sexual. Enfermeiros, médicos, biólogos e psicólogos têm sido os principais agentes de educação sexual. Mais uma vez, se verifica o predomínio de profissionais ligados à área das ciências biológicas preocupados com a sexualidade humana. Mal ou bem, essas pessoas vêm tendo a oportunidade de vivenciar experiências com jovens, adultos e crianças, que podem representar importante ponto de referência, para que novas propostas de educação sexual possam ser criadas.

\section{2 - As Estratégias e o Desempenho do Professor}

Todos os grupos participantes desta pesquisa citam as estratégias utilizadas na realização da educação sexual pela escola como elemento sig- 
nificativo nessa tarefa. Os diretores de escolas e os professores apontam essas estratégias como podendo ser um fato, facilitador ou dificultador da educação sexual na escola pública, conforme elas se caracterizem. Os alunos só se referem àquelas estratégias utilizadas pelos professores, ou pela escola toda, como elemento facilitador de tal tarefa: "A boa convivência entre professor e alunos ajuda na educação sexual." "Quando os alunos confiam no professor tudo fica fácil." "Pessoas palestrantes, que sejam conhecidas na escola, podem ajudar os professores a orientar sobre sexo". "Se a escola tem um psicólogo, facilita a orientação sexual." "A informação correta e aberta ajuda os alunos a terem coragem de fazer perguntas".

Ao priorizar a falta de estratégias adequadas à prática da educação sexual, o professor, parece entender que a maior deficiência, neste caso, não se prende à falta de formação adequada do professor como educador sexual, mas se localiza na falta de indicação de medidas e de modelos que viabilizem a eficácia de suas ações. Embora se digam malformados sexualmente e receosos de enfrentar esse tema junto a seus alunos, esses profissionais se mostram dispostos a executar tal tarefa, se munidos de "receitas e de bulas" traçadas por outras pessoas, supostamente mais preparadas.

Mais uma vez se vê refletir a percepção distorcida do professor, que tenho observado ao longo da minha atuação na capacitação e atuação de docentes das escolas estaduais e municipais. Muitos são os professores que participam desses encontros com o objetivo de encontrar "receitas milagrosa para resolver as suas dificuldades pedagógicas. Esses profissionais têm se mostrado equivocados a respeito da relação dos fundamentos e dos princípios de uma postura profissional e os métodos e estratégias utilizados na operacionalização da mesma. Aqui se repete a dicotomia estabelecida entre dois momentos do fenômeno da práxis educativa.

Quanto a esse fato, um grupo de professores pesquisadores, ligado à Faculdade de Educação, da Universidade de Passo Fundo, RS, confessa não ser fácil superar os embates e dificuldades que, comumente, se estabelecem entre sua prática educativa e a teorização da mesma. Concordo com esses profissionais da educação. Ao não ser consultado sobre questões fundamentais do seu fazer pedagógico e sobre a vida da escola, o professor passa a viver um processo de acomodação e resistência no seu ambiente profissional. Ao ser alijado dos processos decisórios da vida escolar, o professor não se compromete, efetivamente, com as possíveis decisões e implicações que deles advenham. Torna-se então, um mero executor de tarefas pensadas por outras pessoas, muitas vezes estranhas ao ambiente escolar e à vida da comunidade (ANDREOLLA, 1995). 
Vivemos numa sociedade capitalista e ocidental, onde predomina uma visão positivista de ciência. Tal paradignia prioriza o "como fazer" em detrimento do "o que fazer e para que fazer". Daí o predomínio da quantificação e do tecnicisirio. Nesse contexto, alunos e professores passam a ser considerados segundo sua competência no desempenho em usar tecnologias educacionais pré-determinadas pelos verdadeiros pensadores e conhecedores da educação. "Aos professores cabe aguardar as orientações desses sábios e, depois, executar fielmente os procedimentos e os modos de fazer determinados por eles" (MÜLL, 1994, p. 16).

Os reflexos dessa visão de ciência se fazem notar em todos os campos de atuação dos professores. Seja no ensino de Matemática, de História ou na Educação Sexual, o procedimento é o mesmo: o professor fica à mercê de novas modas milagrosas que possam trazer segurança em seu fazer pedagógico.

\section{CONSIDERAÇÕES FINAIS}

Não se pode negar que a sexualidade humana carece de um tratamento sério e adequado tanto por parte da família como por parte da escola. Essa constatação aponta para a necessidade de que mais pessoas estejam efetivamente preparadas para lidar com esse assunto. A preparação tanto de pais como de professores não é coisa que se faça de uma hora para outra. De qualquer maneira, esse desafio precisa ser enfrentado porque pais e professores precisam estar preparados para orientar o novo educando que aí está.

Dados deste trabalho mostram que os professores se encontram na mesma polêmica que vem caracterizando a atual sociedade brasileira: educar as crianças e os jovens dentro da liberdade que sempre desejaram Para si ou reproduzir a educação preconceituosa e autoritária que receberam. Os professores se mostram sensíveis às questões sexuais de seus alunos, mas se confessam temerosos e despreparados para abordá-las (TIBA, 1994).

Não se pode esquecer que esses profissionais pertencem, na sua maioria, a geração dita sanduíche, que se vê na contingência de dar orientações para que seus alunos resolvam situações de vida que eles proprios não viveram. Por seu turno, a formação profissional do professor tem se mostrado pouco preocupada com o tratamento do ser humano como um ser sexuado e displicente com o futuro desempenho desse profissional nesse particular. Dessa forma, o professor se caracteriza como inseguro para lidar 
com alunos reais, trabalhar com gente, pessoas sexuadas, com seus processos normais de desenvolvimento, com suas indagações e conflitos sexuais. Essa situação de desconforto e de insegurança, tanto para alunos como para professores, interfere nas relações intrapessoais e interpessoais tão importantes dentro da escola (SILVA, 1995 ).

Como já mencionei, existe significativa diferença nas respostas dos diferentes segmentos representativos da escola pública sobre os fatores que possibilitam e os fatores que dificultam a educação sexual na escola. As respostas dos diretores de escolas apontam $70 \%$ de dificuldades e $30 \%$ ele possibilidades para que a escola faça a educação sexual de seus alunos; as respostas dadas pelos professores indicam $20 \%$ ele dificuldades e $80 \%$ de possibilidades de a escola pública realizar a educação sexual; as respostas dos alunos revelam um certo equilíbrio entre as dificuldades, $55 \%$, e as possibilidades existentes, $45 \%$, para que a educação sexual seja feita pela escola de $1^{\circ}$ Grau.

Os intervenientes que contribuem para este fato podem ter as mais diferentes origens. Pode-se pensar que o desempenho de diferentes funções pelos diversos grupos que compõem os corpos docente e dicente da escola, interfere nas formas de sentir, de aprender e de se envolver com os acontecimentos do mundo escolar. Parece haver um pacto silencioso entre os integrantes de cada grupo para a defesa interna do mesmo e, conseqüentemente, a transferência de responsabilidades por possíveis dificuldades no desempenho. Muito poucos são os sujeitos desta pesquisa que revelam alguma tentativa de ação conjunta da escola no sentido de atender a orientação sexual de seus alunos.

Ao manifestar a predominância de fatores que dificultam a realização da educação sexual na escola, os diretores parecem buscar justificativas para a inexistência de ações efetivas por parte da escola nesse sentido: "Não existem programas sérios sobre o assunto."

Em seu trabalho sobre educação sexual na escola pública Andaló (1995). citando Cavalcanti, ressalta que o fundamental para que aconteça a educação sexual na escola não são os programas, mas as atitudes. Tais atitudes são concebidas como resultantes da vontade de o indivíduo agir, de forma favorável ou desfavorável, em relação a um determinado objeto. Maximizando os fatores que dificultam a ação da escola pública na educação sexual (70\%), os diretores de escolas parecem querer, não só justificar sua omissão, mas também salvaguardar a própria instituição que representam de possíveis críticas. Dessa forma, o diretor de escola revela assumir acriticamente as características da mesma, contribuindo para a manutenção de suas omissões e suas deficiências. 
Os professores desta região, ressaltando os fatores que possibilitam a educação sexual na escola (80\%), embora se declarem inseguros e eles preparados para assumir tal tarefa, se mostram mais abertos às necessidades dos alunos e das comunidades. Embora não coloquem de modo direto a sua formação como o principal impedimento para que possam fazer a educação sexual de seus alunos, esses profissionais ressaltam as estratégias que utilizam como o principal fator dificultador dessa tarefa. Se tais estratégias se mostram inadequadas, parece evidente que é porque a Sua formação profissional não lhe oferece os subsídios necessários para criar outras ou melhorar as já existentes.

Dessa forma, mais uma vez o professor chama para si, de modo indireto, a maior responsabilidade pela não realização da educação sexual, o professor revela a situação paradoxal que vive no seu dia-a-dia: já está acostumado a ser culpado pelos problemas e desvios nos possíveis projetos, nos quais não teve chance de ser ouvido (ANDREOLLA, 1995).

Se por um lado os professores não demonstram, nesta pesquisa, significativa preocupação com as dificuldades e conflitos a respeito da sexualidade com as quais os alunos aportam à escola, por outro, esses profissionais manifestam temor quanto à reação que os pais possam ter à educação realizada pela escola. Ao mesmo tempo que parecem desconsiderar a ação educativa da família, admitem que a mesma tem posições definidas sobre a educação de seus filhos.

Ao desvelar sua formação pessoal e profissional como os pontos particularmente deficientes, os professores apontam caminhos a serem seguidos por aqueles que perseguem alternativas de melhoria da educação sexual na escola: promover formas de maior e mais efetiva formação do profissional da educação como educador sexual.

A proposta de formação do educador sexual por certo não pode se restringir à incorporação de receitas prontas. Elas envolvem a pesquisa, pelo próprio professor, dascondições reais do universo da clientela, a busca de embasamento teórico que possibilile a análise e a compreensão dos seus achados e, conseqüente, a montagem de estratégias alternativas para essa realidade.

A criação de medidas que possibilitem a formação de educadores sexuais nos cursos de preparação de professores ou fora deles, a implementação da orientação sexual e da educação sexual em todos os níveis de escolaridade representam alternativas viáveis e fundamentais para que as pessoas passem a ver seu corpo e sua sexualidade livres de ansiedade e de preconceitos. 
Para que seja aumentada a eficácia desses trabalhos, entre outras, precisam ser consideradas as seguintes questões:

- a contextualização da clientela a que se destina cada programa as origens das pessoas, as experiências por elas vivenciada bem como suas idades, são informações fundamentais que podem ser obtidas pelo educador, através de levantamentos de dados, de pesquisas e de encontros de estudos;

- a parceria escola-família - a insegurança que essas duas instituições vêm mostrando no tratamento das questões da sexualidade de seus educandos representa um fator indicador da necessidade de ações educativas conjuntas e complementares entre elas;

- o caráter de continuidade das ações de orientação e de educação sexuais - a continuidade dos encontros possibilita que as distâncias entre a clientela e o educador sejam diminuídas e o clima de confiança a de franqueza se estabeleça entre eles. Assim sendo, o trabalho será gratificador e mais eficaz;

- os conteúdos a serem trabalhados - esses conteúdos devem fazer parte do universo do interesse da clientela e não ser estabelecido a priori pelo professor;

- a atitude do educador - uma das questões mais difíceis, senão a mais difícil, de ser encarada é a postura do educador sexual na relação com seus educandos. Há sempre uma certa indagação sobre coisas como: quando falar e quando calar, dar a informação ou deixar que os alunos a encontrem. Vale lembrar que o importante é criar oportunidades de discussão e de trocas de experiências entre os educandos e entre estes e o educador;

- a universalidade de compromisso dos professores -predominantemente os professores da área biológica e os professores de educação religiosa têm assumido a responsabilidade da orientação e da educação sexual. A questão sexual do ser humano está presente em todos as facetas da sua vida. Os problemas que dela decorrem têm reflexos na sociedade como um todo. Portanto, não se entende que profissionais ligados a outras ciências como a Sociologia e a Filosofia permaneçam isentos dessa preocupação. Estudos interdisciplinares e grupos multiprofissionais representam excelentes alternativas de abordagem da sexualidade humana nas escolas. 


\section{REFERÊNCIAS BIBLIOGRÁFICAS}

1. ANDALÓ, Carmen S. A. Um Trabalho sobre sexualidade na escola pública. Revista Brasileira de Sexualidade Humana. v. 6, n. 2, jul/dez, p. 151-159, SBRASH. São Paulo: lglu, 1995.

2. ANDREOLLA. Neusa e outros. A escola de periferia no olhar do professor pesquisador. Revista Espaço Pedagógico. v. 2, n. 1, p. 31-62. Passo Fundo: UPF, Faculdade de Educação, 1995.

3. CUNHA, F. Deusas, Bruxas e Parteiras. Porto Alegre: SOLIVROS, 1994.

4. FERNÁNDEZ. Alícia. La sexualidad atrapada de la señorita maestra. Buenos Aires: Nueva Visión, 1992.

5. FERREIRA, Berta W. Adolescência, Teoria e Pesquisa. Porto Alegre: Sulina, 1984.

6. FÓRUM NACIONAL DE EDUCAÇÃO E SEXUALIDADE. Guia de Orientação Sexual: diretrizes e metodologia. São Paulo: Casa do Psicólogo, 1994.

7. MOLL, Eldon H. Reflexões sobre Pressupostos Filosóficos-metodológicos da Educação. O Fazer Pedagógico. Programa Interinstitucional de lntegração da Universidade com a Educação. Ijui: UNIJUI. 1993.

8. REICH. Wilhelm. A Revolução Sexual. Rio do Janeiro: Guanabara, 1988.

9. SILVA, Cenira Ribeiro. Experiências Puberais e Sexualidade Feminina: subsídios para a educação sexual. Dissertação de Mestrado. Porto Alegre: PUCRS. 1995.

10. SUGAR, Max. Adolescência Atípica e Sexualidade. Porto Alegre: Artes Médicas. 1992.

11. TiBA, lçami. Adolescência: o despertar do sexo. São Paulo: Gente, 1994.

12. VITIELLO. Nelson. Sexualidade e Reprodução na Adolescência. Revista Brasileira de Sexualidade Humana. v. 5, n. 1, p. 15-27. jan/jun - Sociedade Brasileira de Sexualidade Humana. São Paulo: Iglu, 1994. 